\title{
Use of Mass Spectrometry with Electrospray Ionization and Exploratory Analysis for Classification of Extra Virgin Olive Oil Adulterated with Vegetable Oils

\author{
Mitsutake, H.; Gontijo, L. C.; Santana, F. B.; Guimarães, E.; Rocha, L. L.; \\ Borges Neto, $\mathbf{W}$.
}

Rev. Virtual Quim., 2015, 7 (6), 2180-2189. Data de publicação na Web: 22 de julho de 2015

http://www.uff.br/rvq

\author{
Emprego da Espectrometria de Massas com Ionização por Electrospray e Análises \\ Exploratórias para Classificação de Óleo de Oliva Extra Virgem Adulterado com Óleos \\ Vegetais
}

Resumo: Devido ao valor econômico e benefícios à saúde do óleo de oliva extra-virgem (EVOO), este produto é alvo de adulteração principalmente através da adição de óleos vegetais mais baratos. Assim, este estudo avaliou a adulteração de amostras de óleo de oliva extra virgem por óleos de canola, girassol, milho e soja, empregando análise multivariada exploratória. Os perfis químicos das amostras obtidos por espectrometria de massas com ionização por eletrospray no modo positivo (ESI(+)-MS) foram analisados por Análise de Componentes Principais (PCA) e Análise de Agrupamento Hierárquico (HCA). Por meio da análise do gráfico de pesos obtidos na PCA, foi possível identificar as razões $\mathrm{m} / \mathrm{z}$ mais importantes para distinguir óleos autênticos e adulterados, e associar-lhes a composição destas amostras. As amostras autênticas e adulteradas foram classificados em diferentes grupos pelos dois métodos, indicando que as metodologias desenvolvidas são alternativas para o controle de qualidade de óleo de oliva extra virgem.

Palavras-chave: Óleo de oliva extra virgem; adulteração; óleos vegetais; PCA; HCA.

\begin{abstract}
Due to the economic value and health benefits of the extra virgin olive oil (EVOO), this product is mainly the subject of adulteration by addition of cheaper vegetable oils. Thus, this study evaluated the detection of extra virgin olive samples oil adulterated with oils of canola, sunflower, corn and soybeans through exploratory multivariate analysis. The oil fingerprints were obtained by mass spectrometry with electrospray ionization in positive ion mode (ESI(+)-MS). The mass spectrometry data were analyzed by Principal Component Analysis (PCA) and Hierarchical Cluster Analysis (HCA). Through the analysis of the loadings obtained in the PCA, it was possible to identify the ratio $\mathrm{m} / \mathrm{z}$ most important for distinguishing authentic and adulterated oils, as well as the composition related with these samples. Authentic and adulterated samples were classified into different groups by the two methods, indicating that the developed methodologies are alternatives for the quality control of extra virgin olive oils.
\end{abstract}

Keywords: Extra virgin olive oil; adulteration; vegetable oils; PCA; HCA.

* Universidade Federal de Uberlândia, Institute of Chemistry, Campus Santa Mônica, CEP 38408100, Uberlândia-MG, Brasil.

Mquilucas10@gmail.com

DOI: $\underline{10.5935 / 1984-6835.20150129}$

Rev. Virtual Quim. |Vol 7| | No. 6| |2180-2189| 


\section{Use of Mass Spectrometry with Electrospray Ionization and Exploratory Analysis for Classification of Extra Virgin Olive Oil Adulterated with Vegetable Oils

\author{
Hery Mitsutake, ${ }^{a}$ Lucas C. Gontijo, ${ }^{\mathrm{a}, \mathrm{b}, *}$ Felipe B. de Santana, ${ }^{\mathrm{a}}$ Eloiza \\ Guimarães, ${ }^{a}$ Lilian Lúcia da Rocha, ${ }^{c}$ Waldomiro Borges Neto ${ }^{a}$ \\ a Universidade Federal de Uberlândia, Institute of Chemistry, Campus Santa Mônica, CEP \\ 38408-100, Uberlândia-MG, Brasil. \\ ${ }^{\mathrm{b}}$ Instituto Federal de Educação Ciência e Tecnologia Goiano, Rodovia Geraldo Silva \\ Nascimento, km 2.5, CEP 75790-000, Urutaí-GO, Brasil. \\ ' Universidade Federal de Juiz de Fora, Department of Chemistry, Institute of Exact Sciences, \\ CEP 36036-900, Brasil. \\ *quilucas10@gmail.com
}

\section{Introduction}

\section{Materials and Methods}

\subsection{Samples}

2.2. ESI-MS analysis

2.3. Statistical analysis

\section{Results and discussion}

\section{Conclusions}

\section{Introduction}

Extra virgin olive oil (EVOO), one of the fundamental ingredients of the Mediterranean diet, has beneficial health effects, especially due to its high amount of antioxidants, and the presence of oleic acid and linoleic acids. ${ }^{1-3}$ According to the International Council of Olive Oil (IOC), ${ }^{4}$ EVOO is olive oil extracted using only mechanical and physical processes, and whose free acidity, expressed as oleic acid, is not more than $0.8 \mathrm{~g} / 100 \mathrm{~g}$. The consumption of EVOO has increased worldwide over recent decades. It is one of the most expensive vegetable oils, and is thus subject to adulteration, especially by the addition of vegetable oils of a lower price. In countries that produce EVOO, the main adulterant is refined olive oil or olive waste, while in importing countries, this fraudulent practice is mainly from the addition of cheaper seed oil and available on the local. ${ }^{1,5}$ In a newsletter about the market that the IOC publishes monthly, Brazil appears as one of the main importers of olive oil (IOC 2015), ${ }^{6}$ 
which makes this product the object of adulteration mainly by adding oils of local oilseeds, such as soybean, corn, canola, and sunflower. ${ }^{7}$ Because of these possibilities, it is necessary to develop methodologies that can detect possible adulteration in EVOO. However, due to the complexity of the chemical composition of the oils in general, the development of such methodologies is an important challenge in analytical chemistry. ${ }^{5,8}$

The application of spectroscopic techniques in olive oil analysis can be found in the literature. Galtier et al. ${ }^{9}$ applied the near infrared spectroscopy (NIR) along with chemometric methods such as the Soft Independent Modeling of Class Analogy (SIMCA) and Partial Least-Squares Discriminant Analysis (PLS-DA) in order to classify olive oils in relation to geographical origin, obtaining classifications that varied from 68 to $100 \%$ correct. Gurdeniz and Ozen $^{10}$ used a mid-infrared spectroscopy (MIR) for the detection and quantification of EVOO adulteration with canola and cotton oils and a corn-sunflower oils binary mixture, using Principal Component Analysis (PCA), PLS-DA and Partial Least Squares regression (PLS) in the range of $5 \%$ to $20 \%(v / v)$; they obtained good results in classification and standard error of prediction (SEP) smaller than $1.32 \%(\mathrm{v} / \mathrm{v})$ in PLS. Calvano et al. ${ }^{11}$ described the use of matrix-assisted laser desorption ionization time-of-flight mass spectrometry (MALDI-TOF) and extraction of the phospholipids for detecting EVOO adulteration with hazelnut oil, which detects the adulteration in the range of 1 to $20 \%$ (v/v).

Electrospray ionization mass spectrometry (ESI-MS) requires little or no sample preparation, and consists of a soft, fast, versatile, and reproducible ionization technique used mainly for polar molecules, ${ }^{5,12}$ which has motivated their use in the analysis of various complex matrices and fingerprinting analysis. Nunes and Guerreiro $^{13}$ used ESI-MS allied to PCA for the analysis of Brazilian green propolis, which verified the effect of seasonality on the composition of propolis samples. Catharino et $a .^{5}$ applied ESI-MS and PCA to differentiate olive, soybean, corn, canola, sunflower and cotton oils, obtaining distinct groups in scores graphics. Alves et al. ${ }^{14}$ described the use of ESI-MS and PCA to distinguish authentic EVOO of EVOO adulterated with pure olive oil, where it was possible to detect the adulteration in the range of $1 \%$ to $20 \%(\mathrm{w} / \mathrm{w})$. Alves et al. ${ }^{15}$ discriminated authentic EVOO of EVOO adulterated with various types of vegetable oils, obtaining good results of classification $100 \%$ correct, and also used PLS-DA along with ESI-MS.

The objective of this study was to evaluate the use of mass spectrometry with electrospray ionization in positive ion mode (ESI(+)-MS) allied with multivariate exploratory analysis by principal component analysis (PCA) and Hierarchical Cluster Analysis (HCA) to distinguish between authentic samples of EVOO and the EVOO adulterated with canola, sunflower, corn and soybean oils in the range of 1 to $20 \%(w / w)$.

\section{Materials and Methods}

\subsection{Samples}

Commercial samples of extra virgin olive, soybean, corn, sunflower and canola oils were acquired at local stores. The adulterated mixtures were prepared by the addition of adulterant oils (soy, corn, sunflower and canola) in binary mixtures with EVOO and concentrations ranging from 1 to $20 \%(w / w)$ with increments of $2 \%(w / w)$, yielding a total of 10 samples for each type of adulterant oil (total of 50 samples).

For this type of analysis, a pre-treatment is necessary to improve the extraction and detection of analytes in equipment. The use of extraction water/methanol allows selective extraction of major free fatty acids and phenolic compounds, wherein the first are considered markers of purity and provenance, and the last are important for 
antioxidant activity exhibited by EVOO., ${ }^{5,16}$ For this, aliquots of $100 \mu \mathrm{L}$ of each sample were transferred to $1.5 \mathrm{~mL}$ tubes followed by the addition of $1 \mathrm{~mL}$ of a solution of deionized water (Mili-Q, Millipore, Schwalbach, Germany)/methanol (HPLC grade, Merck, São Paulo, Brazil) 1:1 (v/v) with $1.0 \%$ of formic acid. The extraction was carried out under vigorous stirring for $30 \mathrm{~s}$ on a vortex apparatus (Phoenix AP-56, Araraquara, SP, Brazil). All the extractions were performed in triplicate. After phase separation, the aqueous-methanolic phase was analyzed in the mass spectrometer.

\subsection{ESI-MS analysis}

The aqueous-methanolic phase was injected with a microsyringue directly into the ESI ion source of the mass spectrometer with ion trap analyzer (LCQFleet, ThermoScientific, San Jose, CA, USA). The analyses were performed in the positive ion mode and typical conditions were as follows: flow injection rate of $10 \mu \mathrm{L} \mathrm{min}{ }^{-1}$, capillary temperature $300{ }^{\circ} \mathrm{C}$, capillary voltage of $30 \mathrm{~V}$ and cone voltage of $3.0 \mathrm{kV}$. The mass spectra were collected in the $100-1200 \mathrm{~m} / \mathrm{z}$ range. ${ }^{14,15}$

\subsection{Statistical analysis}

The data matrix $m \times n$ was constructed where $m$ is the number of samples and $n$ is the number of mass-to-charge ratios $(\mathrm{m} / \mathrm{z})$. To discard noise signals, tested models with ions whose relative abundance were greater than 5, 10, 15 and $20 \%$. Of those, the best result produced was $15 \%$, and therefore only ions with relative abundance greater than 15 $\%$ were included in the final data matrix. Multivariate analyses were performed by Principal Component Analysis (PCA) and Hierarchical Cluster Analysis (HCA), using MATLAB version 6.1 (Mathworks, Inc., Natick, MA, USA) and PLS_Toolbox version 3.5 (Eigenvector Research Inc., Wenatchee, WA, USA).
After excluding outliers samples by graphic of $Q$ residuals versus Hotelling $T^{2}$, experimental data generated a final matrix of 47 samples ((a) ten samples of EVOO authentic, (b) ten samples of EVOO adulterated with soybean oil, (c) ten samples of EVOO adulterated with canola oil, (d) nine samples of EVOO adulterated with corn oil, and (e) eight samples of EVOO adulterated with sunflower oil) and 1100 variables $(\mathrm{m} / \mathrm{z}$ ratios and relative intensities of the detected ions). The PCA and HCA were used to evaluate the similarity between the authentic samples and samples adulterated by forming different groups according to their authenticity and adulterant oil.

\section{Results and Discussion}

The ESI-MS technique helps to obtain information about compounds of higher molecular weights, e.g., polyphenols. ${ }^{13}$ All samples of EVOO, authentic and adulterated, were analyzed by ESI-MS in positive ion mode. Figure 1 shows ESI(+)-MS fingerprints of an authentic sample of EVOO (Figure 1a), and EVOO adulterated with $1 \%$ of canola, sunflower, corn and soybean oil (Figures $1 \mathrm{~b}$ to $1 \mathrm{e}$, respectively). Although the identification of compounds that gave rise to a particular $m / z$ is not necessary for the classifications by PCA and HCA, the ESI(+)-MS fingerprints allow the identification of some ions by comparison with previously published works. The $m / z 121,137,165,225,243,283$, 417, 877 and 903 refer to tyrosol $(\mathrm{M}+\mathrm{H}-$ $\left.\mathrm{H}_{2} \mathrm{O}\right)^{+}$, hydroxytyrosol $\left(\mathrm{M}+\mathrm{H}-\mathrm{H}_{2} \mathrm{O}\right)^{+}$, coumaric, sinapic, elenoic and oleic acids, $\beta, \gamma-$ tocopherol, dioleyl-1-palmitoilglycerol $\left(\mathrm{M}+\mathrm{NH}_{4}\right)^{+}$and triolein $\left(\mathrm{M}+\mathrm{NH}_{4}\right)^{+}$, respectively. ${ }^{2,5,16,17}$ Most of these identified compounds are among those responsible for antioxidant activity presented by EVOO. . $^{818-20}$ According Vaclavik et al. ${ }^{17}$ peaks with $\mathrm{m} / \mathrm{z}$ higher than 800 refers to triacylglycerol; peaks with $m / z$ between 497 and 603 are the diacylglycerols, and peaks with $\mathrm{m} / \mathrm{z}$ 286-339 range represent monoacylglycerols. 
Furthermore, EVOO, for not being a refined oil, shows in its $\mathrm{ESI}(+)-\mathrm{MS}$ fingerprints the characteristics $m / z 121,137,417,433$ and 449. Observing the graphs in Figure 1, the adulteration of EVOO with refined vegetable oils shows changes in the relative intensities of the ions; however, ions considered characteristic of both the refinement process
( $m / z$ 85, 149, 181, 351, 377, 395, and 397) as the oils of soybean $(\mathrm{m} / \mathrm{z} 193,233,273,396$, and 445$)$, canola ( $m / z 195,279,317$ and 349) and sunflower ( $\mathrm{m} / \mathrm{z} 269$ and 355), do not appear in the fingerprints of adulterated EVOO, which complicates the identification of adulterant oil used in the process. ${ }^{5}$

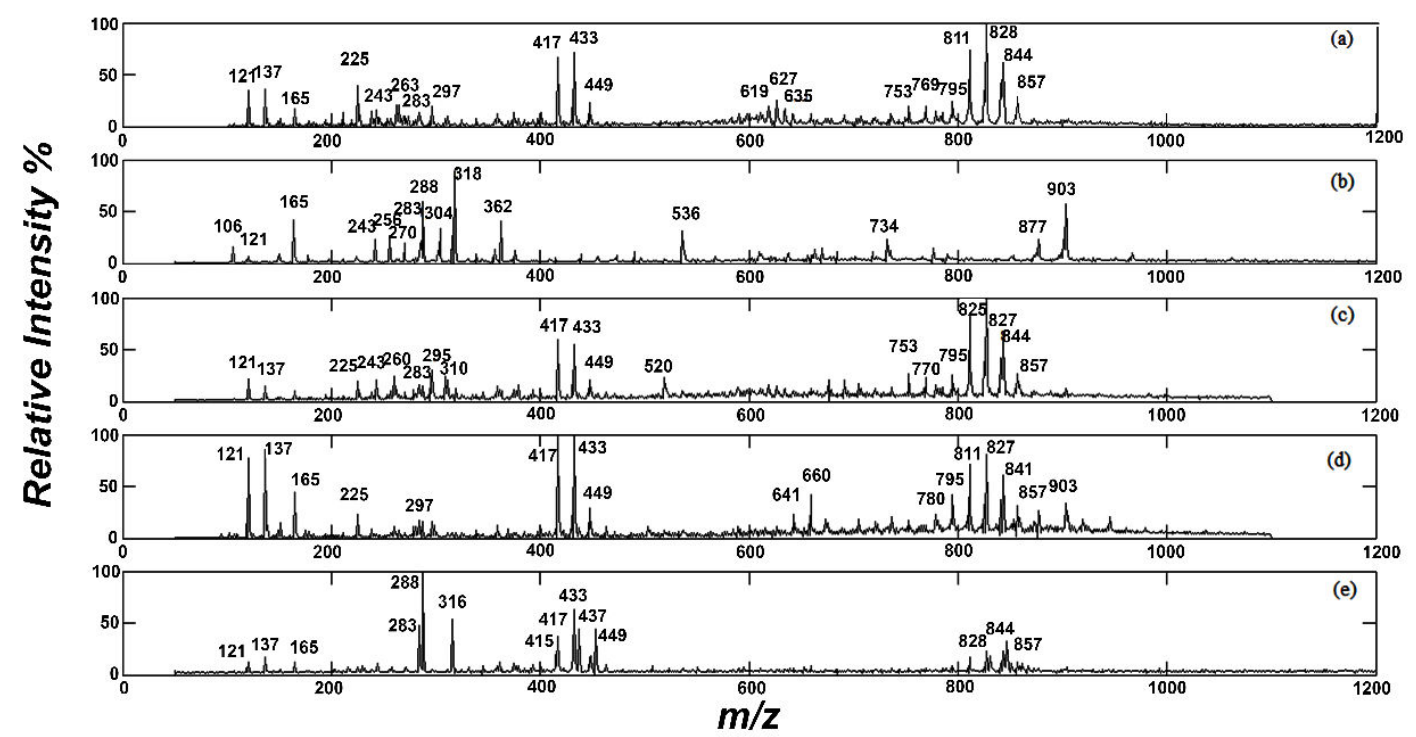

Figure 1. ESI(+)-MS fingerprints of samples of EVOO: (a) authentic and adulterated with $1 \%$ $(\mathrm{m} / \mathrm{m})$ of :(b) canola oil; (c) sunflower oil; (d) corn oil; (e) soybean oil

The best PCA model was constructed using the data centered on the average, and using seven Principal Components (PC's), which showed $89.90 \%$ of variance captured. The use of fewer components would not be a good distinction between the groups, and most PCs did not capture relevant information for distinction of groups. A better view of the distinction of groups of samples was obtained by the scores graphs of PC1 $\times$ PC2 $\times$ PC3, as shown in Figure 2, where we notice the clear separation and classification of groups of authentic and adulterated samples. According to this graph, the PC1 separates authentic samples in relation to adulterated samples with oils of soybean, canola and corn. PC2 was already responsible for the separation of the group of EVOO adulterated with corn and sunflower oil, while the PC3 separates the authentic samples in relation to all adulterations, except those made with sunflower oil. This graph also shows that the group with the greatest similarity with the authentic EVOO fingerprints concern samples adulterated with sunflower oil, where only small differences in PC2 were able to make this distinction. 


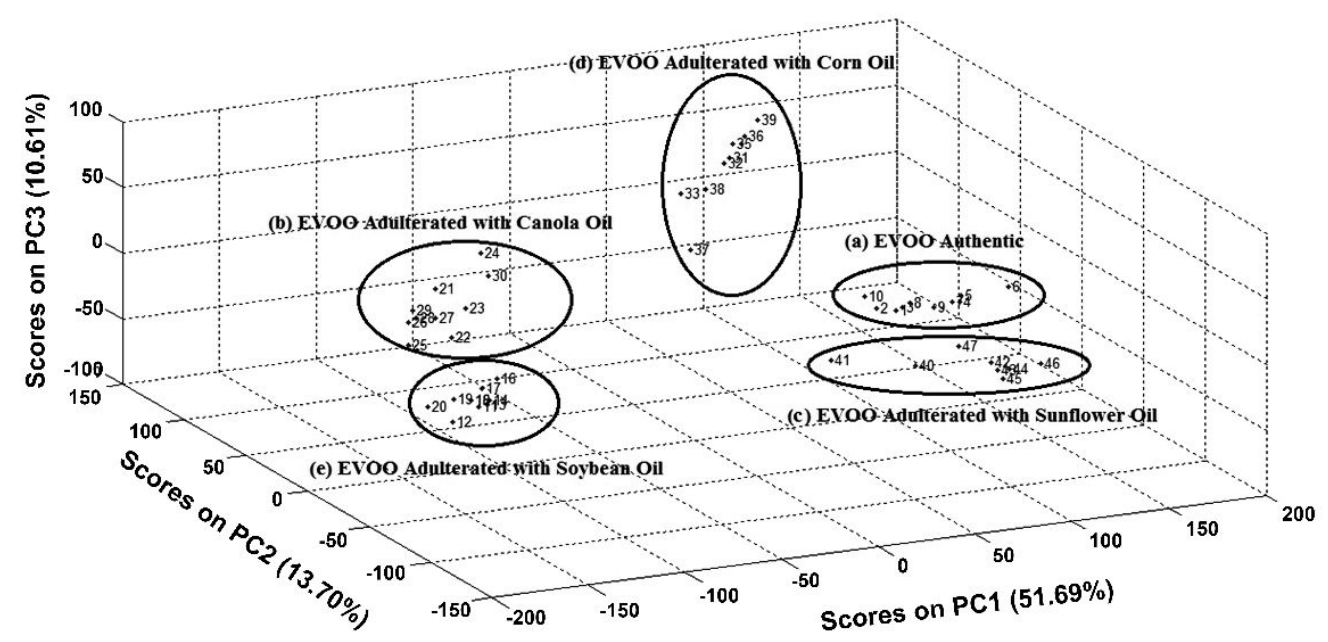

Figure 2. Scores graphs of PC1 $\times$ PC2 $\times$ PC3 for the groups: (a) EVOO authentic, (b) EVOO adulterated with canola oil, (c) EVOO adulterated with sunflower oil, (d) EVOO adulterated with corn oil, e (e) EVOO adulterated with soybean oil

HCA was used to construct a dendogram from the data that was not scaled, and using the nearest neighbor distance $K$, which is shown in Figure 3. In this figure, the EVOO adulterated with soybean, canola and corn oil showed a distinct separation of authentic EVOO. However, the group of samples adulterated with sunflower oil were not well classified by HCA, in which the samples 40 and 41 were considered more similar to authentic oils than samples belonging to their group, and one sample classified outside of the group of adulterant (sample 42, adulterated with $3 \%(w / w)$ of sunflower oil). However, none of these samples was classified as an outlier by $Q$ residuals versus Hotelling $\mathrm{T}^{2}$ graphic of PCA (data not shown) and so were not excluded from the constructed model. This result is also consistent with the PCA obtained in Figure 2, where the highest similarity of the authentic EVOO group refers to adulterated oil with sunflower oil. 


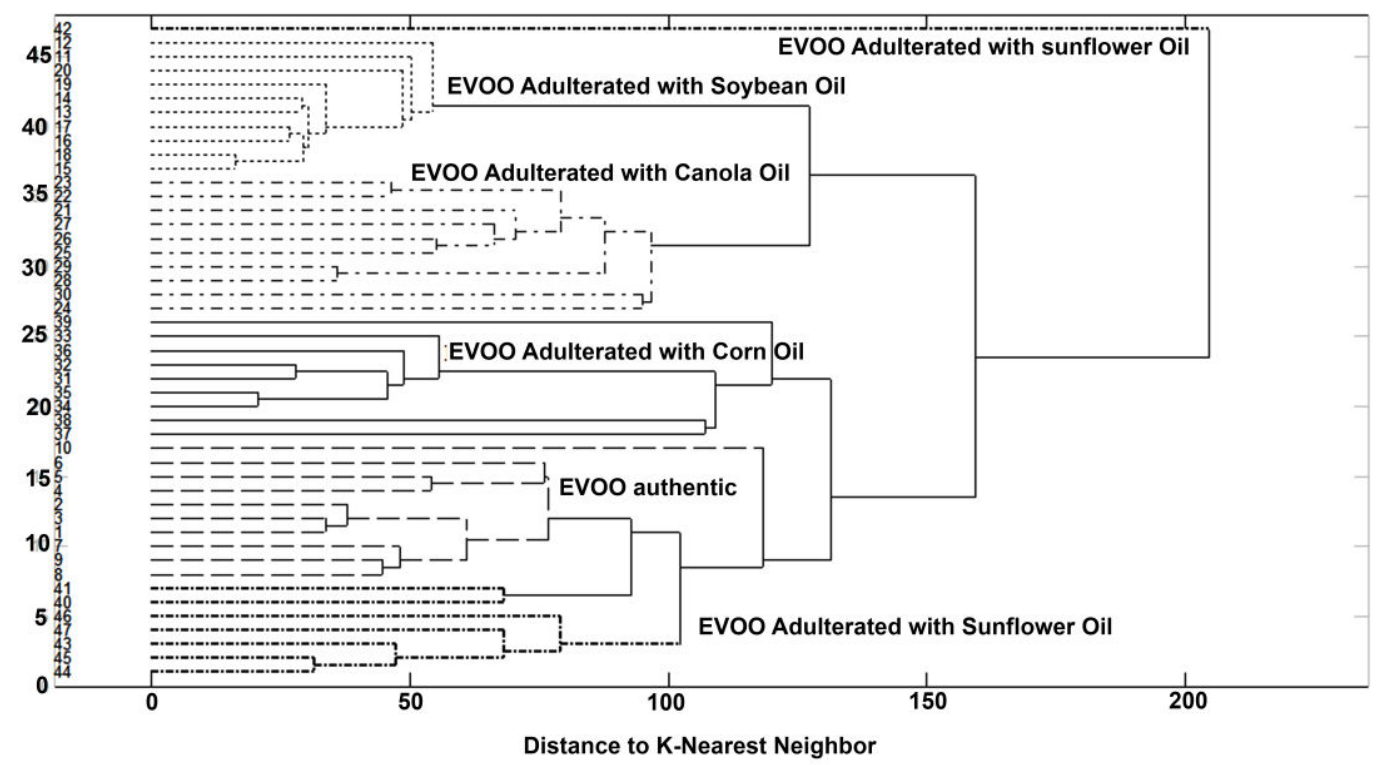

Figure 3. Dendrogram for samples of EVOO obtained from the ESI(+)-MS fingerprint and built with data not scaled and distance and K-Nearest-Neighbor

Observing the graphs of weight in the first three PCs obtained by PCA (Figure 4), it appears that 29 variables $(\mathrm{m} / \mathrm{z} 121,137,164$, $165,225,243,260,288,297,309,311,316$, $318,417,422,433,437,643,659,753,769$, $795,811,827,841,843,844,877$ and 903) are the most relevant to explaining the overall data set of 1100 ions. In these graphs, it can be seen that the $\mathrm{m} / \mathrm{z} 121$ and 137 , referring to tyrosol and hydroxytyrosol, were important in these three PCs, indicating that the variation of the concentration of these two compounds in the samples was important to distinguish the groups. Other $m / z$ that proved to be important in these three PCs was the triolein $(\mathrm{m} / \mathrm{z}$ of 903 , $\left[\mathrm{M}+\mathrm{NH}_{4}\right]^{+}$), which according to Gomez-Ariza et al. ${ }^{2}$, is the most abundant triacylglycerols in olive oils; another triacylglycerol that proved to be important in this separation was the dioleyl-1-palmitoilglycerol $(\mathrm{m} / \mathrm{z} \quad 877$ $\left[\mathrm{M}+\mathrm{NH}_{4}\right]^{+}$) (Figure 4c). The $\mathrm{m} / \mathrm{z} 165,243$ and 417 , referring to compounds coumaric and elenoic acid and $\beta, \gamma$-tocopherol, respectively, were also important for distinguishing the clusters. Furthermore, most of the ions identified as typical of unrefined oils (such as the EVOO), cited above, have shown to be important in the graphs of the weights. The amount of sinapic acid $(\mathrm{m} / \mathrm{z} 225)$ was significant only on PC1, being important for performing the differentiation of adulteration with sunflower and canola oil. Other $\mathrm{m} / \mathrm{z}$ relevant for the PCA were not attributed to any specific compound, but may be related to the variation in the amount of tri-,di- and monoacylglycerols due to the presence of adulterant oils in EVOO. ${ }^{17}$

Therefore, from graphs shown in Figure 4, it is found that the $m / z$ relevant for the identification and characterization of EVOO played a key role in the discrimination of authentic and adulterated samples. However, the characteristic $m / z$ of the refining process, or even the adulterant oils did not have the same relevance to this discrimination. It highlights the importance of tyrosol, hydroxytyrosol and triolein in this study, phenolic alcohols and triacylglycerol of great importance to the quality and characterization of EVOO. 

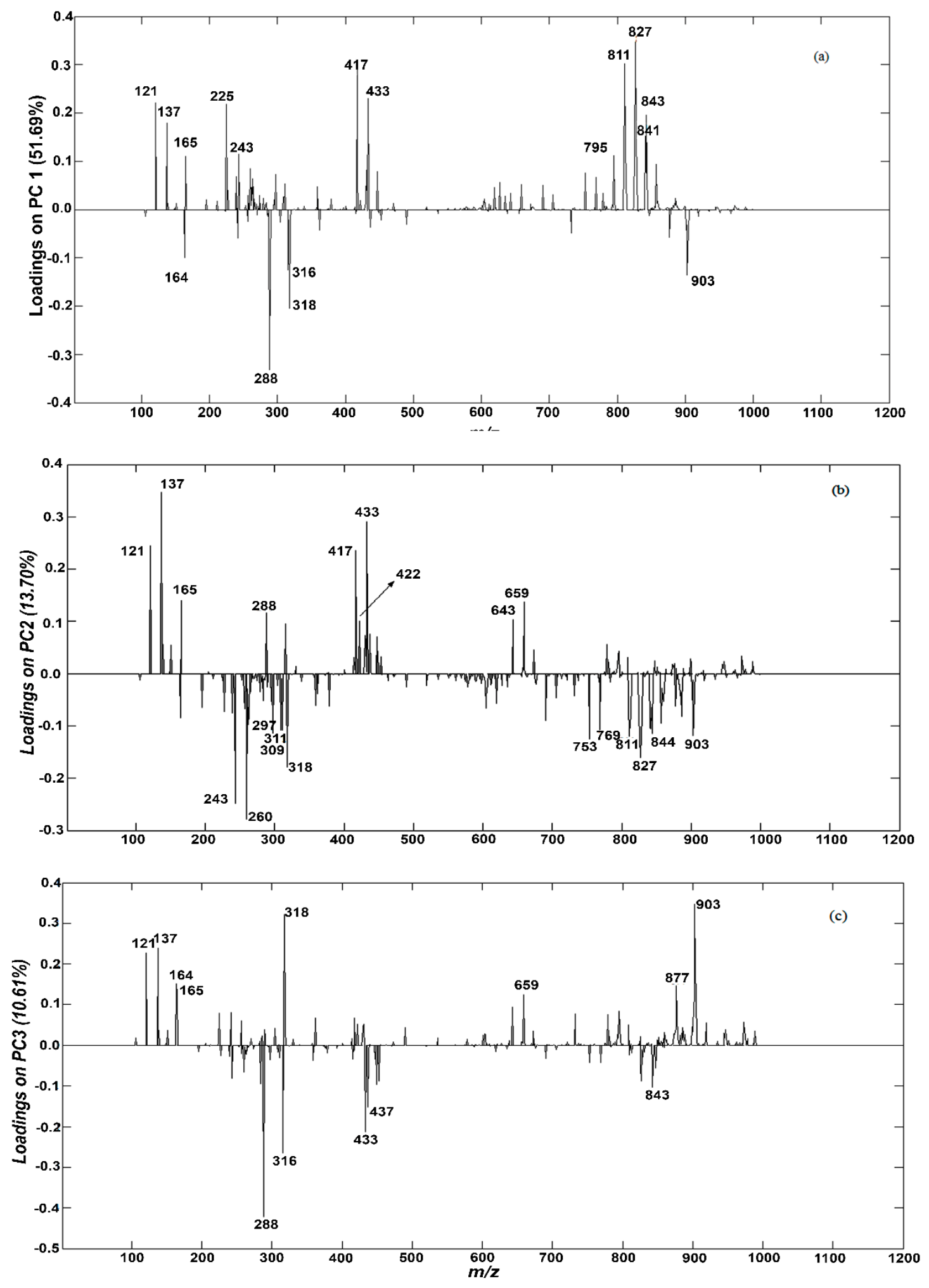

Figure 4. Graphs of weight showing the importance of the main variables $(\mathrm{m} / \mathrm{z})$ on the first three PCs: (a) PC1 (b) PC2, and (c) PC3. The values of $m / z$ and their respective relative intensities were obtained from ESI(+)-MS fingerprints of EVOO samples 


\section{Conclusions}

Applying direct infusion technique ESI(+)MS in conjunction with the chemometrics methods of exploratory analysis PCA and HCA, it was found that the proposed method was able make a distinction between authentic and adulterated EVOO, demonstrating the formation of different groups according to their authenticity and presence of adulterants (canola, sunflower, corn and soybean oils). The application of HCA was not as efficient as PCA, but did show a promising technique in the quality control, since has detect all adulterations, except performed with sunflower oil. The developed methodologies were simple, fast, and precise, capable of detecting the adulteration of extra virgin olive oil by vegetable oil in the range of 1 to $20 \%(w / w)$, indicating a viable technique for quality control.

\section{Acknowledgement}

The authors would like to thank CAPES, CNPq and FAPEG for financial support.

\section{References}

${ }^{1}$ Casale, M.; Oliveri, P.; Casolino, C.; Sinelli, N.; Zunin, P.; Armanino, C.; Forina, M.; Lanteri, S. Characterisation of PDO olive oil Chianti Classico by non-selective (UV-visible, NIR and MIR spectroscopy) and selective (fatty acid composition) analytical techniques. Analytica Chimica Acta 2012, 712, 56. [CrossRef] [PubMed]

${ }^{2}$ Gomez-Ariza, J. L.; Arias-Borrego, A.; GarcíaBarrera, T.; Beltran, R. Comparative study of electrospray and photospray ionization sources coupled to quadrupole time-of-flight mass spectrometer for olive oil authentication. Talanta 2006, 70, 859. [CrossRef] [PubMed]

${ }^{3}$ Rohman, A.; Che Man, Y. B.; Farahwahida Mohd, Y. The use of FTIR spectroscopy and chemometrics for rapid authentication of extra virgin olive oil. Journal of the American Oil Chemists' Society 2014, 91, 207. [CrossRef]

${ }^{4}$ International Olive Council. Trade standard applying to olive oils and olive-pomace oils. Available

at:

$<$ http://www.internationaloliveoil.org/docum ents/viewfile/3615-normaen1>. Accessed: 26 January 2015.

${ }^{5}$ Catharino, R. R.; Haddad, R.; Cabrini, L. G.; Cunha, I. B. S.; Sawaya, A. C. H. F.; Eberlin, M. $N$. Characterization of vegetable oils by electrospray ionization mass spectrometry fingerprinting: classification, quality, adulteration, and aging. Analytical Chemistry 2005, 77, 7429. [CrossRef] [PubMed]

${ }^{6}$ International Olive Council. Market newsletter. Available at: < http://www.internationaloliveoil.org/docume nts/viewfile/10139-market-newsletter-may2015>. Accessed: 2 July 2015.

${ }^{7}$ Fasciotti, M.; Pereira Netto, A. D. Optimization and application of methods of triacylglycerol evaluation for characterization of olive oil adulteration by soybean oil with HPLC-APCI-MS-MS. Talanta 2010, 81, 1116. [CrossRef] [PubMed]

${ }^{8}$ Frankel, E. N. Chemistry of extra virgin olive oil: adulteration, oxidative stability, and antioxidants. Journal of Agricultural and Food Chemistry 2010, 58, 5991. [CrossRef] [PubMed]

${ }^{9}$ Galtier, O.; Abbas, O.; Dréau, Y. L.; Rebufa, C.; Kister, J.; Autaud, J.; Dupuy, N. Comparison of PLS1-DA, PLS2-DA and SIMCA for classification by origin of crude petroleum oils by MIR and virgin olive oils by NIR for different spectral regions. Vibrational Spectroscopy 2011, 55, 132. [CrossRef]

${ }^{10}$ Gurdeniz, G.; Ozen, B. Detection of adulteration of extra-virgin olive oil by chemometric analysis of mid-infrared spectral data. Food Chemistry 2009, 116, 519. [CrossRef]

${ }^{11}$ Calvano, C. D.; Ceglie, C. D.; D'Accolti, L.; Zambonin, C. G. MALDI-TOF mass spectrometry detection of extra-virgin olive oil adulteration with hazelnut oil by analysis of phospholipids using an ionic liquid as matrix and extraction solvent. Food 
Chemistry 2012, 134, 1192. [CrossRef] [PubMed]

${ }^{12}$ Soares, I. P.; Russo, R. M. O.; Prates, R. G. D.; Augusti, R.; Fortes, I. C. P.; Pasa, V. M. D. Avaliação da eficiência das técnicas ESI-MS e ATR/FTIR na determinação de adulteração de BX com querosene e óleo residual. Química Nova 2011, 34, 1439. [CrossRef]

${ }^{13}$ Nunes, C. A.; Guerreiro, M. C. Characterization of Brazilian green propolis throughout the seasons by headspace GC/MS and ESI-MS. Journal of the Science of Food and Agriculture 2012, 92, 433. [CrossRef] [PubMed]

${ }^{14}$ Alves, J. O.; Neto, W. B.; Mitsutake, H.; Alves, P. S.; Augusti, R. Extra virgin (EV) and ordinary (ON) olive oils: distinction and detection of adulteration (EV with $\mathrm{ON}$ ) as determined by direct infusion electrospray ionization mass spectrometry and chemometric approaches. Rapid Communications in Mass Spectrometry 2010, 24, 1875. [CrossRef] [PubMed]

${ }^{15}$ Alves, J. O.; Botelho, B. G.; Sena, M. M.; Augusti, R. Electrospray ionization mass spectrometry and partial least squares discriminant analysis applied to the quality control of olive oil. Journal of Mass Spectrometry 2013, 48, 1109. [CrossRef] [PubMed]

${ }^{16}$ Law, W. S.; Chen, H. W.; Balabin, R.; Berchtold, C.; Meier, L.; Zenobi, R. Rapid fingerprinting and classification of extra virgin olive oil by microjet sampling and extractive electrospray ionization mass spectrometry. Analyst 2010, 135, 773. [CrossRef] [PubMed]

${ }^{17}$ Vaclavik, L.; Cajka, T.; Hrbek, V.; Hajslova, J. Ambient mass spectrometry employing direct analysis in real time (DART) ion source for olive oil quality and authenticity assessment. Analytica Chimica Acta 2009, 645, 56. [CrossRef] [PubMed]

${ }^{18}$ García-Rodríguez, R.; Romero-Segura, C.; Sanz, C.; Pérez, A. G. Modulating oxidoreductase activity modifies the phenolic content of virgin olive oil. Food Chemistry 2015, 171, 364. [CrossRef] [PubMed]

${ }^{19}$ Siger, A.; Czubinski, J.; Dwiecki, K.; Kachlicki, P.; Nogala-Kalucka, M. Identification and and antioxidant activity of sinapic acid derivatives in Brassica napus $L$. seed meal extracts. European Journal of Lipid Science and Technology 2013, 115, 1130. [CrossRef]

${ }^{20}$ Paiva-Martins, F.; Fernandes, J.; Santos, V.; Silva, L.; Borges, F.; Rocha, S.; Belo, L.; SantosSilva, A. Powerful Protective Role of 3,4Dihydroxyphenylethanol-Elenolic Acid Dialdehyde against Erythrocyte OxidativeInduced Hemolysis. Journal of Agricultural and Food Chemistry 2010, 58, 135. [CrossRef] [PubMed] 